\title{
Cooperative Monitoring of Regional Security Agreements
}

\author{
Arian L. Pregenzer, Michael Vannoni, and Kent L. Biringer \\ Nonproliferation and Arms Control Analysis Department \\ Sandia National Laboratories \\ P.O. Box 5800, MS0567 \\ Albuquerque; New Mexico 87185-0567
}

Arian L. Pregenzer is a physicist who heads the Nonproliferation and Arms Control Analysis Department and the Cooperative Monitoring Center at Sandia National Laboratories, in Albuquerque, New Mexico. Her primary interest is the role of technology in achieving cooperative security objectives. Prior experience includes representation of the U.S. Department of Energy on chemical weapons negotiations and research on lithium ion sources for particlebeam-driven inertial confinement fusion.

Michael Vannoni is a mechanical engineer and senior member of the technical staff at Sandia National Laboratories. His background includes work in nuclear reactor safety, nuclear and hazardous materials transportation, and nuclear weapons production. Current work includes analysis of technically-based regional security arrangements.

Kent Biringer is a mechanical engineer and senior member of the technical staff at Sandia National Laboratories. His background includes research in solar and fossil energy, systems analysis, arms control and nonproliferation. He currently analyzes cooperative monitoring options for arms control and nonproliferation agreements.

This work was suponted by the United

States Department of Energy under

Contract DE-ACO4-94AL85000.

\section{DISCLAIMER}

\footnotetext{
This report was prepared as an account of work sponsored by an agency of the United States Government. Neither the United States Government nor any agency thereof, nor any of their employees, makes any warranty, express or implied, or assumes any legal liability or responsibility for the accuracy, completeness, or usefulness of any information, apparatus, product, or process disclosed, or represents that its use would not infringe privately owned rights. Reference herein to any specific commercial product, process, or service by trade name, trademark, manufacturer, or otherwise does not necessarily constitute or imply its endorsement, recommendation, or favoring by the United States Government or any agency thereof. The views and opinions of authors expressed herein do not necessarily state or reflect those of the United States Government or any agency thercof.
} 


\begin{abstract}
This paper argues that cooperative monitoring plays a critical role in the implementation of regional security agreements and confidence building measures. A framework for developing cooperative monitoring options is proposed and several possibilities for relating bilateral and regional monitoring systems to international monitoring systems are discussed. Three bilateral or regional agreements are analyzed briefly to illustrate different possibilities: (1) the demilitarization of the Sinai region between Israel and Egypt in the 1970s; (2) the 1991 quadripartite agreement for monitoring nuclear facilities among Brazil, Argentina, The Argentine-Brazilian Agency for Accounting and Control of Nuclear Materials and the International Atomic Energy Agency; and (3) a bilateral Open Skies agreement between Hungary and Romania in 1991. These examples illustrate that the relationship of regional or bilateral arms control or security agreements to international agreements depends on a number of factors: the overlap of provisions between regional and international agreements; the degree of interest in a regional agreement among the international community; efficiency in implementing the agreement; and numerous political considerations.
\end{abstract}

Given the importance of regional security to the international community, regions should be encouraged to develop their own infrastructure for implementing regional arms control and other security agreements. A regional infrastructure need not preclude participation in an international regime. On the contrary, establishing regional institutions for arms control and nonproliferation could result in more proactive participation of regional parties in developing solutions for regional and international problems, thereby strengthening existing and future international regimes. Possible first steps for strengthening regional infrastructures are identified and potential technical requirements are discussed. 


\section{Cooperative Monitoring of Regional Security Agreements}

Since the end of the Cold War, the emphasis on regional security has increased significantly. There is a widespread perception that without the stability provided by a system of states dominated by two super-powers, local conflicts over military balance of power, resources, disputed territory and ethnic antagonisms are more likely to escalate into violent conflict. Regional wars can have global consequences, especially when the countries involved possess weapons of mass destruction.

In the last two decades, the United States, Europe and the former Soviet Union have recognized the vital role played by arms control and confidence building measures in enhancing security. Although some other states and regions are may be uneasy with the concept that arms control and increased openness can enhance security, some acknowledge the need to decrease regional conflict, and are beginning to consider new options. In the Middle East multilateral peace process, the Arms Control and Regional Security (ACRS) working group is discussing potential regional arms control and confidence-building measures. In South Asia, India and Pakistan have implemented a hotline agreement and have negotiated several other military confidence building measures such as the notification of military exercises. South America has led the regional arms control process with the Treaty of Tlatelolco, which prohibits nuclear weapons in Latin America, and with the quadripartite agreement for monitoring nuclear facilities among Brazil, Argentina, The Argentine-Brazilian Agency for Accounting and Control of Nuclear Materials (ABACC) and the International Atomic Energy Agency (IAEA). In Northeast Asia, informal discussions of regional security agreements are in process.

These regional discussions involve a broad spectrum of issues, ranging from nuclear arms control to environmental protection. In the initial stages of regional security discussions, it is important to identify issues where progress is possible. Even if the primary regional arms control concern is nuclear weapons, the first series of discussions may need to focus on less volatile issues, such as the environment, conventional weaponry, or disaster response. In regions where 
tensions are high, limiting armaments or ceasing controversial weapons development programs may only become possible after considerable confidence building in other areas. Table I illustrates potential discussion topics for regional arms control and confidence building measures.

\begin{tabular}{|l|l|l|}
\hline \multicolumn{3}{|c|}{$\begin{array}{c}\text { Table I. Potential Discussion Topics for Regional Arms Control } \\
\text { and Confidence Building Measures }\end{array}$} \\
\hline \multicolumn{1}{|c|}{ Nuclear } & \multicolumn{1}{|c|}{ Conventional } & \multicolumn{1}{c|}{ Delivery Systems } \\
\hline $\begin{array}{c}\text { Fissile material production } \\
\text { cutoff }\end{array}$ & Demilitarized zones & Missile non-deployment \\
\hline Reactor closure & Arms reductions or limitations & Missile destruction \\
\hline $\begin{array}{c}\text { Nuclear weapon-free zone } \\
\text { Material disposition and } \\
\text { safeguards }\end{array}$ & $\begin{array}{c}\text { Pre-notification/observation of } \\
\text { military exercises }\end{array}$ & Missile production limitations \\
\hline Test limitations & Ancidents at Sea Agreements & Missile test limitations \\
\hline Nuclear emergency response & Military exchange programs & $\begin{array}{l}\text { Pre-notification of missile } \\
\text { launches }\end{array}$ \\
\hline
\end{tabular}

\section{Regional Versus Global}

Many regional discussions occur against a backdrop of multilateral or global arms control initiatives. In such cases, the question of the relationship of the regional to the global agreement often arises. Many arms control analysts emphasize the over-riding importance of global agreements, especially those which concern nuclear issues, and stress that regional agreements should be embedded in a global context. However, regional agreements can have advantages over their global counterparts.

First, where political issues impede participation in global treaties, a regional agreement may be the only viable solution in the near term. The series of agreements between Argentina and Brazil regarding the cessation of nuclear weapon programs provides a good example.

Second, regional agreements can be tailored to meet particular concerns of regional parties. For example, a regional verification regime might be needed for a Middle East nuclear weapon free zone, because existing IAEA measures may be perceived as inadequate for assuring compliance. 
Third, regional agreements sometimes can be negotiated more rapidly than global agreements. The bilateral Open Skies Agreement between Hungary and Romania and the Wyoming Memorandum of Understanding on the destruction of chemical weapons between the United States and the former Soviet Union demonstrate this point.

Fourth, some issues are purely regional in nature. While a third party may be requested to monitor compliance with agreements in some regions, such as the demilitarization of the Sinai between Egypt and Israel, some would argue that the Israeli agreement to withdraw from occupied territory is an inherently regional issue. The issue of control over Kashmir is also a largely regional issue between India and Pakistan.

It is important to keep in mind that participation in regional or bilateral agreements does not preclude participation in global arrangements. Indeed, a regional or bilateral regime may be a stepping stone or a necessary first step. It is possible to imagine a global nuclear weapon dismantlement program for which bilateral agreements between the U.S. and the former Soviet Union, such as START and INF, provide a starting framework.

Long-term effectiveness of regional security agreements ultimately will depend on the commitment and day-to-day involvement of regional parties. Although an external presence may remain important in many regions, it will not obviate the need for a strong indigenous infrastructure for both the development and the implementation of region-specific options for arms control and confidence-building measures. An institutional infrastructure is needed to support the analysis of policy options and the process of negotiating agreements. Implementation of agreements will require a technical infrastructure that could include the development of monitoring technologies, a communications network for exchanging information, data analysis capabilities and a trained inspector. 
Technically-Based Cooperative Monitoring Supports Implementation of Agreements

Implementing agreements often involves technically-based cooperative monitoring. Such monitoring can strengthen existing agreements and set the stage for continued progress. An agreement among two or more countries may bring about a temporary equilibrium in their relations, but energy must be invested to make the equilibrium a lasting one. Investing time and resources in cooperatively monitoring the terms of an agreement can contribute significantly to its stability and permanence. Such an investment signals that the agreement is regarded as important and that countries are committed to its success. Cooperative monitoring also provides a method of openly documenting compliance with the terms of an agreement and makes any act of noncompliance difficult to ignore. Although an external party can assume partial responsibility for monitoring the terms of an agreement, participation of regional parties will strengthen the regime.

Cooperative monitoring involves the collecting, analyzing and sharing of information among parties to an agreement. Technologies incorporated into a cooperative monitoring regime must be sharable among all parties, and all parties must receive equal access to data or information acquired by the system. A cooperative monitoring regime also should include procedures for dealing with anomalous data and false positives. Such procedures are necessary for constructively resolving problems and are likely to involve human presence and activity.

Many monitoring technologies developed for other national security purposes in the United States and elsewhere are neither export controlled nor classified and are applicable to a broad spectrum of regional arms control and confidence-building applications. Examples include technologies for detection and assessment, such as unattended ground sensor systems, aerial overflight systems and commercial satellite systems; technologies for data security, such as data authentication and tamper indication; and technologies for access control. When combined with data management, analysis and integration capabilities, these technologies provide powerful tools for implementing regional agreements. They enable parties to observe relevant activities, to define and measure agreed-upon parameters, to record and manage information, and to perform inspections. 
In addition to the purely technical benefits, the availability of standardized monitoring systems to all parties to an agreement can remove personal bias, minimize suspicion and balance the ability to detect and analyze relevant information. This is particularly important when parties to an agreement have differing indigenous technical capabilities. Providing all parties with an acceptable minimum monitoring capability will strengthen commitment to the terms of an agreement and contribute to an atmosphere of mutual trust and peaceful resolution of conflict. In addition, the use of remote monitoring technology sometimes can reduce the frequency of inspections, thereby decreasing the intrusiveness and increasing the efficiency of the monitoring regime.

Because of its sharability, the results of cooperative monitoring can have great utility in open discussions of compliance, but additional information also may be important. Countries that participate in cooperative monitoring arrangements usually retain the sovereign right to make compliance decisions, using all available information, including that collected from purely national means. Cooperative monitoring should be seen as a supplement, not a replacement, for a country's national capabilities.

\section{First Steps in Establishing Technical Infrastructure}

Competence with monitoring technology and procedures is essential for the full involvement of regional parties. Lack of knowledge can undermine commitment to an agreement and can impede effective use of technology. In addition, regional competence will enable parties to propose their own solutions to regional problems. Not only is familiarity with monitoring technology needed during the negotiation and implementation phase of an agreement, it will be needed to maintain monitoring systems after implementation. Thorough understanding of monitoring technology also can alleviate concerns that monitoring systems might be gathering more information than stipulated by the terms of the agreement. To be full participants, each country will need its own cadre of technical experts. 
Educating regional parties about a range of verification and monitoring technologies and training them to design and operate monitoring systems for particular applications will be an important first step. Although many countries have achieved significant technical capability, applying technology to cooperative monitoring of arms control or other agreements is often a new concept. Even highly technical countries may need help in exploring options for regional confidence-building measures and developing technical monitoring options. For less technically advanced countries, achieving familiarity with monitoring technologies and options may require significant investment in education and training.

Effective education and training should include in-depth discussion of technical issues involved in establishing a monitoring system, as well as experience with monitoring hardware, software, and data processing and integration capabilities. In particular, participants in a training program should gain experience with using systems of technologies to accomplish specific objectives. Understanding how to manipulate and analyze data from remote monitoring sites and to display it in a form that facilitates decision-making will be critical. Computer-assisted cooperative monitoring games, based on the more traditional "war-game" idea, could provide another useful training tool for experimenting with monitoring options. Appendix A describes the Cooperative Monitoring Center, an experimental program at Sandia National Laboratories, to assist in the education and training process.

\section{Technical Collaborations on Monitoring Applications}

Because technology plays an important role in implementing agreements, it can be a particularly fruitful area for collaboration. Not only do technical collaborations provide neutral ground for interaction among scientific communities, they may also produce results that will aid in implementing future agreements.

Trial confidence-building measures or "cooperative monitoring experiments" can provide a good context for collaborative work. A cooperative monitoring experiment is a technical collaboration on collecting and sharing data relevant to a monitoring application. The object is to 
familiarize participants with monitoring techniques and procedures. The experiments on sharing seismic data internationally, conducted by the Group of Scientific Experts in preparation for a Comprehensive Test Ban, is a good example of a large-scale cooperative monitoring experiment. Much smaller scale experiments are also possible.

Monitoring experiments provide a forum for collaborations among technical communities and also produce results that can aid policymakers in the formulation of potential agreements. Experiments provide the opportunity to investigate monitoring options in a neutral environment and adjust procedures and technologies to meet regional needs. Experience from experiments form a base for a comprehensive agreement when future political conditions permit. Interpersonal relationships resulting from collaboration further support the confidence-building process. Most important, monitoring experiments are practical steps that can be taken during the phase between expressing an interest in a cooperative agreement and implementing it.

There are a number of potential applications for monitoring experiments. These include monitoring of cross-border traffic, demilitarized zones, nuclear facilities, and the environment. Initially, it might be wise to experiment with monitoring of legitimate, allowed activities, with the intention of establishing mechanisms for providing transparency (or verification) under potential unilateral, regional, or international agreements.

\section{Elements of a Technical Infrastructure}

Regardless of the degree to which technology is used in a regional agreement, a technical infrastructure will greatly facilitate implementation. The primary functions will be communication among parties to an agreement, and data collection, analysis and management.

Communication Network A communication network among parties to an agreement is essential and relatively little equipment is required to support the exchange of routine, formalized information. For example, equipment at the Nuclear Risk Reduction Centers in the United States and Russia (which manage information exchange under a number of bilateral and international agreements) consists of computer monitors, word processors, facsimile machines, phone lines and 
printers; communication links are provided by satellite. More sophisticated capabilities would be required to collect and transmit data from remote monitoring systems associated with confidence building measures or other agreements.

The number of communication channels will depend on the number of different categories of exchanged information. Separate channels would be needed to support bilateral and multilateral communications, official and unofficial communications, and emergency and routine communications. To prevent unauthorized access and ensure privacy, computer security systems that permit "multi-level security" of exchanged information could be needed. For example, this would allow two countries to carry out a private bilateral exchange of information on the same system used by other countries.

Data Management and Analysis An organized system for providing access to exchanged information is highly recommended. Data bases with text search and retrieval capabilities facilitate the organization of basic information, such as points of contact in participating countries, the text of mutual agreements, and reports on inspections or fact-finding missions. If countries are in the process of implementing confidence building measures that make use of technical monitoring, equipment and procedures for data acquisition, integration, and analysis, will be required. This will entail more sophisticated communication and software capabilities. Depending on the nature of the confidence building measures and the regional monitoring network, the system could receive data directly from the sensors deployed for cooperative monitoring applications, or such data could be transmitted to the center after being initially processed at local data acquisition centers. The communication network could provide the basis for data transmission and communication of analytic results to local data centers in each country.

\section{Framework for Developing Cooperative Monitoring Options}

The design of a cooperative monitoring system is rarely separable from the political process. Balancing political concerns and technical capabilities can be frustrating to technologists accustomed to designing the "best" technical solution. If cooperative monitoring is incorporated 
into a regional agreement, it is critical to understand the following four issues: (1) the context for a potential agreement, (2) potential or actual provisions of the agreement, (3) observables associated with the provisions, and (4) technical options for monitoring the agreement.

1. The context of a potential agreement includes the desired list of participants, understanding regional concerns and politics, and understanding the top-level goals of an agreement. If the primary goal of an agreement is to initiate a regional dialogue, a rigorous monitoring regime may be premature.

2. Cooperative monitoring provides evidence relevant to specific agreement provisions, such as prohibited activities and declarations. General statements about the objectives of potential verification measures are also included as treaty provisions. If an agreement forbids the production of a particular item, but does not provide for a verification process, developing cooperative monitoring options will be a moot point.

3. Understanding the observable physical phenomena that can be measured to assess compliance with the provisions of an agreement is an essential step in determining monitoring technologies. Observables include both items or activities limited by the agreement and their observable signatures.

4. Designing acceptable cooperative monitoring options requires identifying technologies that can detect relevant observables, weighing the tradeoffs between monitoring intrusiveness and system vulnerability, and considering other constraints, such as costs.

\section{Examples of Regional Arms Control and Confidence Building Agreements}

Three examples of arms control and confidence building agreements that have been implemented on a regional basis will be discussed in this section: (1) the demilitarization of the Sinai region between Israel and Egypt in the 1970s; (2) the 1991 quadripartite agreement for monitoring nuclear facilities among Brazil, Argentina, The Argentine-Brazilian Agency for Accounting and Control of Nuclear Materials (ABACC) and the International Atomic Energy Agency (IAEA); and (3) a bilateral Open Skies agreement between Hungary and Romania in 
1991. Each of these agreements illustrates different ways a regional agreement can interface with international treaties and different roles that third parties or international bodies can assume in a regional agreement. They also illustrate different approaches to the use of technical monitoring.

\section{Military Disengagement in the Sinai: Israel and Egypt}

\section{Context}

The June 1967 Arab-Israeli war ended with Israel in full control of the Egyptian Sinai peninsula up to the Suez Canal. In October 1973, an Arab coalition attacked Israel with the intent of regaining occupied territory. The war ended somewhat inconclusively on the Sinai front with Israeli and Egyptian forces on both sides of the canal.

A formal cease-fire was signed on Nov. 11, 1973. However, the cease-fire line was not acceptable to the Egyptians as a long-term solution. Seeking to avert further hostilities, U.S. Secretary of State Henry Kissinger initiated a process whereby Israel slowly removed its troops from the region. The primary goal was to return occupied land to Egypt, while maintaining Israeli security by assuring sufficient early warning of attack. The process resulted in two disengagement agreements, known as Sinai I and Sinai II. Although Egypt and Israel were the only parties to the agreements, the United States played a major role in their negotiation and implementation. Each side felt that the presence of US troops was necessary: both as a symbol of US commitment to the agreement and as a military presence to enforce the agreement should problems arise.

\section{Provisions}

The first Sinai Disengagement Agreement (Sinai I) was signed on January 18, 1974 and required the Israelis to withdraw to approximately $20 \mathrm{~km}$ from the Suez canal. A thin buffer zone was established, and limited force zones were created on both sides of the buffer zone. The U.S. and the UN supported the agreement as third parties. The U.S. supported the UN with aerial surveillance flights.

The Sinai II Agreement, again negotiated with the support of Secretary Kissinger, was signed on September 4, 1975. In Sinai II, Israel agreed to withdraw from the strategic Giddi and 
Mitla pass region in exchange for a mix of third party monitoring by the U.S. and the UN to provide tactical warning, combined with self-verification by Israel and Egypt. The key point of contention was the control of the high ground of the Giddi and Mitla passes in west-central Sinai and the Israeli signal collection stations there. These passes are the primary avenues for large, offensive forces to move across the peninsula. The Israeli government, reinforced by its experience in the 1973 war, wanted significant early warning to mobilize a defense against a pending threat.

\section{Observables}

Military hardware and personnel are the observables associated with both of these agreements. No military equipment or personnel were allowed in the demilitarized zones; and numbers were restricted in the limited force zones.

\section{Monitoring}

A Joint Commission and Liaison System, incorporating representatives from all parties and chaired by the Chief Coordinator of the UN peacekeeping mission, was established to supervise and coordinate implementation of the agreement. Israel and Egypt each established a signal collection station on the ridge-line near the passes and were permitted to fly reconnaissance missions over their own territory up to the buffer zone. This activity did not constitute cooperative monitoring because they exchanged no information with each other on the basis of this monitoring.

The UN provided 4,000 peacekeeping troops to perform general observation and on-site inspections of garrisons in the limited force zones. The U.S. performed periodic overflights of the disengagement zone for tactical early warning and established the Sinai Support Mission (SFM) to monitor access to the Giddi and Mitla passes. Multiple types of sensors, as shown in Table II (page 12) were employed by the SFM to detect activity in the region and to assist analysts in characterizing the nature of the activity. The SFM transmitted detection and characterization data simultaneously to both the Israel and Egyptian signal stations. 


\section{Table II. Sensors Employed by the Sinai Field Mission}

\begin{tabular}{|l|l|}
\hline Seismic & $\begin{array}{l}\text { The most commonly used type of sensor because of near-ideal conditions in the } \\
\text { desert soil. The battery-powered MINISID-III could detect vehicles at } 500 \mathrm{~m} \text { and } \\
\text { personnel at } 50 \mathrm{~m} \text { range. It transmitted the seismic signal by radio to an adjacent } \\
\text { watch station. }\end{array}$ \\
\hline Acoustic & $\begin{array}{l}\text { This system was a modular addition to the MINISID-III and used its radio } \\
\text { transmission system. A seismic activation of sufficient duration activated the unit } \\
\text { which could detect personnel to } 30 \text { m and vehicles to } 100 \text { m range. }\end{array}$ \\
\hline Magnetic & $\begin{array}{l}\text { This system was also a modular addition to the MINISID-III and could detect a } \\
\text { person with a rifle at } 3 \text { - } 4 \text { m and a medium truck at 15 - 20 m. }\end{array}$ \\
\hline Strain & $\begin{array}{l}\text { A strain sensitive cable was buried under roads and main trails and could be up to } \\
\text { several hundred meters long. The compression caused by the passage of an } \\
\text { object induced a signal proportional to weight to be generated and transmitted to a } \\
\text { watch station. }\end{array}$ \\
\hline Infrared \\
Break-Beam & $\begin{array}{l}\text { The directional infrared intrusion detector (DIRID) was also used to monitor roads } \\
\text { and large paths. The system consisted of a transmitter and receiver for two } \\
\text { parallel infrared beams. DIRID was mounted on tripods above ground and could } \\
\text { monitor a space } 3 \text { to 17 m wide. Passage of an object through the beam broke the } \\
\text { circuit and caused an activation. The order of beam breakage indicated the } \\
\text { direction of movement. }\end{array}$ \\
\hline Imaging Infrared & $\begin{array}{l}\text { A prototype system called Passive Confirming Scanner was used during 1977-78 } \\
\text { to counter low-visibility conditions in dust and fog. The system was removed } \\
\text { because of unacceptable reliability. }\end{array}$ \\
\hline beyond visual line of sight.
\end{tabular}

The system performed quite reliably although periodic refinements were necessary. On average, there were 200 sensor activations a day, almost all of which resulted from permitted activity or natural occurrences. Activations were caused by support vehicles for the SFM and Israeli and Egyptian stations, movement of UN peace keepers, natural seismic disturbances, low- 
flying aircraft, wildlife, and nomadic Bedouins. All reported violations were relatively minor, unintended, and easily resolved.

After a period of initial suspicion, the Sinai front stabilized and monitoring activities became almost routine. Political leaders in both countries eventually praised the SFM. The right combination of technical measures and manned operations proved to be vital to the success of the operation. The increased level of confidence resulting from the Sinai monitoring and the impartial role of the U.S. and the UN were major contributors to the Egypt-Israel Peace Accord (the "Camp David Agreement") of March 1979. Camp David resulted in a phased Israeli withdrawal from the Sinai completed in April 1982. As the Israelis withdrew eastward and relations improved, there was no need for intensive monitoring of the passes and the system was shut down in January of 1980. Total cost of the SFM during its operation was $\$ 92.7$ million U.S. dollars.

After the Peace Accord was signed, Israel and Egypt requested that the SFM continue its monitoring role, but in a somewhat different fashion. The SFM now performed on-site inspection and low-altitude aerial surveys. Israel and Egypt continued the practice of de facto selfverification during the withdrawal period. Israel maintained four signal collection stations along ridges in the central Sinai, and both countries performed reconnaissance flights up to the line of disengagement. The Israeli withdrawal took place very smoothly with only 29 minor violations cited by the SFM. In April 1982, the Multinational Force and Observers (MFO) was formed to succeed the SFM and to perform peacekeeping and monitoring functions. A Military Joint Commission was established and the MFO continued to maintain liaison offices in both Egypt and Israel. The force, consisting of 2,500 multinational troops, maintained watch stations with attended optical devices but without remote monitoring. The MFO also performed periodic lowlevel aerial surveys and on-site inspections in limited force zones. The Israel/Egypt border is currently stable, and the MFO continues to function in the Sinai so discretely that many people outside the region are unaware of its operations and scope. This may be the best testament to its effectiveness. 


\section{Agreement on Monitoring Nuclear Facilities: Brazil and Argentina}

\section{Context}

Although nuclear arms control in Latin America had been debated since the early 1960s, there was resistance in both countries to sign the Nuclear Nonproliferation Treaty. This is at least partly due to the perception that the treaty unfairly divided the world into nuclear "haves" and "have-nots," and provided insufficient restrictions on the nuclear programs of the former group. Both countries had signed the Treaty of Tlatelolco, a Latin American nuclear weapons free zone agreement, but had not brought it into force. Contentious issues included the transport of nuclear weapons through the zone and the interpretation of peaceful nuclear explosions permitted by the treaty. Throughout this debate, both countries continued nuclear weapon programs, building research and power reactors, nuclear test facilities and missile delivery systems.

After decades of military rule, the 1980s brought a change to civilian government for both Argentina and Brazil. At the same time, export control regulations enacted by the Nuclear Suppliers Group increased the pressure to place nuclear facilities under full scope safeguards. Neither economy was healthy and new governments in both countries wished to redirect resources to domestic problems. The time was ripe for cooperation and confidence building on nuclear issues.

Cooperation on nuclear issues proceeded in a step-wise manner. The first agreement, in 1980 while military governments still prevailed, concerned cooperation on the civilian nuclear fuel and provided for technical collaborations and joint training programs. Technical collaborations increased in scope over the next six years, throughout which time the countries issued several joint statements on nuclear policy.

Only in 1987 did Argentina and Brazil begin to open up facilities related to their nuclear weapon programs. The process began with exchange visits by heads of state to uranium enrichment facilities. They also continued to issue joint declarations regarding the peaceful nature of their nuclear programs and emphasizing the need for confidence building and nuclear cooperation throughout Latin America. By 1990, the Argentine Condor II missile program was 
terminated, and the Brazilians acknowledged the termination of a nuclear bomb program and secret test site in Cachimbo.

\section{Provisions}

The first of a series of agreements specifying provisions for the joint monitoring of nuclear facilities and material was enacted in 1990. Over the next five years, the degree of cooperative monitoring of nuclear facilities gradually increased. In 1991, the countries signed the ArgentineBrazilian Accord on Nuclear Energy, in which they agreed to use nuclear materials and facilities exclusively for peaceful purposes and to prohibit the test, use, manufacture, production, or acquisition of nuclear weapons. Peaceful nuclear explosions were also prohibited, as being indistinguishable from weapons tests. The agreement also provided for the exchange of descriptive lists of all nuclear facilities, declarations of nuclear material inventories, and reciprocal inspections of centralized register systems.

In addition, this agreement established the Argentine-Brazilian Agency for Accounting and Control of Nuclear Materials (ABACC) to administer a Common system for Accounting and Control of Nuclear Materials (SCCC). The register and reporting system of the SCCC would be presented to the IAEA. Responsibilities of the SCCC included:

- maintaining record and inventory systems for nuclear materials,

- establishing measuring systems to determine the nuclear material inventories and their variations,

- evaluating accuracy and calculating uncertainty of measurements,

- establishing procedures for carrying out physical inventory and for determining and evaluating non-accounted material,

- implementing containment and surveillance systems.

ABACC was staffed with 50 inspectors, half provided by each country, and was assigned the responsibility for conducting inspections, designating inspectors, evaluating inspections and concluding international agreements. As of December 1993, 56 inspections had been carried out.

At the end of 1991, this bilateral agreement was supplemented with the Quadripartite Agreement between Brazil, Argentina, ABACC and the IAEA. Although IAEA safeguards had 
and conducting overflights, procedures for data processing and sharing, and methods for resolving disputes. A partial list of provisions is provided below.

\section{Aircraft}

- Both countries will use air force AN-24 and AN-30 twin-engine turbo-props.

- The observing party can use either its own aircraft or one of the host state's.

Monitoring Equipment

- Sensors were limited to optical and video cameras possessed by both parties.

However, provisions were made to allow updating the sensor annex to accommodate new types of sensors.

Procedures and Restrictions

- A request to use the host country's aircraft must be submitted seven days in advance.

- Overflights in hazardous airspace (e.g., artillery ranges) are to be publicly announced and have special flight planning.

- Preflight inspection of the aircraft by the observed country may last no longer than eight hours, and must be completed at least three hours before the start of the flight.

- The quota of flights is four per year in each country.

- The distance and duration of flights is limited to $1,200 \mathrm{~km}$ or three hours whichever comes first.

- Repeated passes over a site or loitering by the aircraft is prohibited.

\section{Data Exchange}

- Two sets of camera films will be developed jointly by technicians at a designated facility in the host country. The observing country takes possession of one film and the host country retains the other. If dual sensors are unavailable, a copy of the original material is given to the observing country.

\section{Resolution of Disputes}

- A Consultative Commission was established to modify provisions where the treaty allows updates and to resolve disputes that may arise in the course of implementing the agreement. Disputes regarding findings are resolved at the ministerial level. 


\section{Observables}

Since there are no treaty-limited activities or items, observables are not related to treaty provisions in the usual manner. However, the military equipment and activities are the primary concerns of parties to Open Skies agreements. In choosing the appropriate technology, its value for detecting such equipment and activities will be the deciding factor.

\section{Monitoring}

In preparation for entry into force of the treaty, a demonstration flight was performed in June 1991. The purpose of the flight was two-fold: (1) to validate the equipment and procedures, and (2) to enhance popular support of the agreement through media coverage. The aircraft was navigated jointly by Hungarian and Romanian officers. France provided technical and operational assistance to both countries. The film camera was a commercially available Frenchbuilt OMERA-33 capable of $10 \mathrm{~cm}$ ground resolution under optimal conditions. French technicians installed the camera and associated equipment and assisted the joint Hungarian/Romanian team in its operation. Seventeen countries participating in the Open Skies negotiations sent observers.

The flight covered military facilities in both countries and included a military college with weapons displayed for this flight, an exercise ground, an abandoned Soviet air base, an operating military airfield, a civilian airfield, a railroad junction, and an ammunition depot. Panchromatic film was used to facilitate rapid development and copying. Video cameras were not used because neither air force had experience with their installation and use in aircraft. The average flight altitude over Hungary was 4,500 feet, but weather conditions in Romania required an average altitude of 1,000 feet with excursions to 800 feet to produce photographs of acceptable quality. Problems occurred with navigation because flight crews lacked detailed charts of sites to be overflown and the multinational crew had difficulty communicating. Neither country expected such major navigational problems, but the trial flight was still considered to be successful.

Multilateral Open Skies negotiations reconvened in September 1991, and significant progress was made in narrowing differences on policy and technical issues. The momentum of the 
successful Hungary-Romania agreement supported the constructive pace of the discussions. The same fundamental issues that Hungary and Romania had faced in their bilateral talks were addressed and compromises were made over the type of sensors to be used, the ownership of aircraft, data processing and distribution, and the geographic scope. The treaty was signed in Helsinki on March 24, 1992. Hungary and Romania have continued their bilateral overflight regime.

\section{Lessons Learned}

Four categories of lessons learned from these agreements can be applied to security discussions in other regions: (1) the relationship of regional agreements to multilateral or global agreements; (2) the importance of setting a pace commensurate with regional political conditions; (3) the contribution of technically-based cooperative monitoring to the implementation of agreements; and (4) the value of regional participation in monitoring the terms of agreements.

\section{Relationship of Regional to Multilateral or Global Agreements}

Although none of the agreements discussed in this section are devoid of international participation, the degree to which extra-regional parties are involved is highly variable. The United States played a key role in negotiating and monitoring the agreement for Israeli withdrawal from the Sinai, and the United Nations was an important presence during implementation. In addition, both sides monitored compliance individually with their own national means. In the case of Argentina and Brazil, only after years of bilateral agreements did they involve the IAEA in the process. International inspections supplement those performed by the bilateral ABACC. In the case of the bilateral Open Skies regime, the bilateral accord was attained as a substitute for a multilateral regime, and stimulated progress in the multilateral forum. There are no plans to subsume the bilateral agreement under the multilateral one when it enters into force.

When regions have a serious concern, they are unlikely to relegate the negotiation and monitoring of an agreement totally to an international body. Most will want direct involvement in 
assuring compliance. In the case of agreements affecting more states than the parties to the agreement, such as agreements involving weapons of mass destruction, the parties are likely to want to assure the international community of their compliance with global norms. In such cases, some stamp of approval from an international body will probably be required. This does not mean that the region must give up regional monitoring arrangements. However, they may need to coordinate their procedures with an international body and provide it with supporting data.

There is growing recognition that bilateral or regional inspections may offer efficient options for achieving the goals of multilateral agreements. For example, the Chemical Weapons Convention explicitly permits bilateral inspections to substitute for multilateral inspections, given approval of the international Organization for the Prohibition of Chemical Weapons. This is to avoid duplication of inspections that are already occurring under agreements such as the Wyoming Memorandum of Understanding between the United States and the former Soviet Union.

\section{Setting the Proper Pace}

Great patience may be required when negotiating agreements with profound consequences for the national security of participating countries. In the case of Argentina and Brazil, first steps focused on technical cooperation on the civilian nuclear fuel cycle. Only much later were defenserelated nuclear facilities discussed, and the first steps only involved exchange visits by the heads of state. Small efforts in technical collaboration and acknowledgment of activities grew into the renunciation of nuclear defense activities and the implementation of safeguards on nuclear material and facilities throughout Argentina and Brazil. This may be a model for nuclear arms control in other regions, such as the Middle East.

A step-by-step approach was also pursued in the series of agreements between Egypt and Israel. Only after successful monitoring of the initial Israeli withdrawal from the Sinai did the sides feel confident enough in the situation to sign the Camp David Peace Accord. 
In the case of the bilateral Open Skies agreement between Hungary and Romania, the perception by both sides of the immediate need for greater transparency led to rapid negotiation and implementation of an agreement.

\section{Contributions of Technically-Based Cooperative Monitoring}

Technically-based cooperative monitoring was utilized by all agreements discussed in the previous section. These technical monitoring systems provide objective data relevant to the terms of the agreements, on which compliance decisions can be based. The data can also be shared with the international community, if desired, to assure others of adherence to certain agreements. Although Israel and Egypt continued to utilize their own national capabilities to monitor the disengagement process, they also jointly relied on shared data provided by the Sinai Field Mission.

Technology cannot substitute for human involvement. It is the right combination of human presence, procedures and technology that contributes to the success of agreements. Although technology can provide objective data, humans are needed to analyze the data and to settle disputes. It is important to keep in mind that the ultimate goal of regional security agreements is reduced tension and warmer relations among participating countries. Human interactions during the implementation of agreements can contribute to this end.

Another key observation is that technical monitoring can be pursued incrementally. The Hungary- Romania bilateral overflight negotiations were successful, in part, because the participants choose to fashion an agreement that recognized available resources but retained the option for future improvements. This incremental approach, using cost-effectiveness as a guide, enabled constructive measures to be taken at a politically sensitive time. Neither country could afford elaborate aircraft or sensor systems. Simple aircraft, familiar to both countries, were chosen which eased the task of procedural definition and preflight inspection. Relatively simple and available optical and video sensors were selected. The use of panchromatic film simplified data processing and exchange. As time has passed, improvements, such as the digitization of image information, have been implemented with the help of third parties such as France. 


\section{Regional Participation Critical for Success}

The success of all three agreements discussed here is largely attributable to the active participation of regional parties in their negotiation and implementation. In no case was an agreement imposed on the region by an outside body or international organization; although the United States played a decisive role in the Israeli/Egypt agreements, and certainly provided resources for cooperative monitoring. One potential weakness of this accord, which may be relevant to future Middle East agreements, was the lack of direct participation of the Israelis and Egyptians in the cooperative monitoring regime. A potential next step would have been to involve both countries in the activities of the Sinai Field Mission. This would not have precluded their continued use of their own national means of verifying the terms of the agreement, but it would have provided for routine contact between technical experts from each country. Such routine contact can be an effective confidence building measure, as has been demonstrated through bilateral inspections between the U.S. and the former Soviet Union.

Argentina and Brazil created an effective infrastructure to support implementation of their bilateral agreements with little assistance from the outside world. The development of this indigenous capability has allowed them to implement the agreements effectively and independently. It also makes them a critical contributor to larger Latin American security discussions and may provide a model for other regions. They rightfully take pride in this accomplishment. 


\section{Summary}

Regional security has assumed new significance in the post Cold War environment. Although the use of arms control and confidence building measures to enhance security originated with the United States, Europe and the former Soviet Union, such measures currently are under discussion in many other regions.

Region-specific approaches to confidence building and transparency will require significant input and innovation of regional parties. Establishing a regional infrastructure for arms control and other cooperative measures will be an important part of this process. Since technology can play an important role in implementing regional security agreements and confidence-building measures, education and training of regional parties in the use of cooperative monitoring technologies should be included.

The Sinai accords in the Middle East, the evolution of nuclear cooperation between Brazil and Argentina, and the bilateral Open Skies agreement between Hungary and Romania illustrate that security arrangements can evolve within a regional context. In each case, the use of appropriate monitoring technologies has been crucial to success. These agreements also illustrate the importance with taking an incremental approach to cooperative agreements: the key is to identify issues on which initial progress is possible, even if these issues are not the ultimate concern. Small steps can open doors.

The Cooperative Monitoring Center at Sandia National Laboratories provides a unique forum for offering hands-on experience with the design and development of monitoring systems that can be used to implement and verify cooperative security arrangements and confidencebuilding measures. Monitoring technologies, including hardware, software, simulation, and data collection and processing can be demonstrated and integrated into specialized applications. 


\section{Acknowledgement}

The authors are grateful to Kerry Herron, of the Nonproliferation and Arms Control Analysis

Department at Sandia National Laboratories, for careful review of this paper.

\section{Bibliography}

\section{Monitoring the Demilitarization of the Sinai}

1) Mandell, Brian; The Sinai Experience: Lessons in Multimethod Arms Control Verification and Risk Management, Arms Control and Disarmament Division, Department of External Affairs, Ottawa, Canada, 1987.

2) U.S. Sinai Support Mission; Watch in the Sinai, Department of State Publication, Number 9131, General Foreign Policy Series 321, June 1980.

3) Comptroller General of the United States; Report to Congress: An Evaluation of the U.S. Early.Warning System in the Sinai, Report D-77-11, June 6, 1977.

\section{Brazil and Argentina: Monitoring Nuclear Material and Facilities}

1. Collina, Tom Zamora, and de Souza Barros, Fernando; "Transplanting Brazil and Argentina's Success;" Institute for Science and International Security; February 1995.

2. Redick, John R., "Argentina and Brazil's New Arrangement for Inspections and IAEA Safeguards," Nuclear Control Institute, February 1992.

\section{The Bilateral Open Skies Agreement between Hungary and Romania}

1. Krasznai, Marton; "Cooperative Bilateral Aerial Inspections: The Hungarian -Romanian Experience," Open Skies, Arms Control and Cooperative Security, Edited by Michael Krepon and Amy Smithson, St. Martin's Press, (1992): pp. 135-146.

2. Krasznai, Marton; "A Bilateral Accord that Helped Resume the Open Skies Conference: The Hungarian-Rumanian Open Skies Agreement," Disarmament, Vol. 15, No. 2 (1992): pp. 176186. 


\section{Appendix A}

\section{The Cooperative Monitoring Center: An Experimental Approach}

In July 1994, Sandia National Laboratories established the Cooperative Monitoring Center to provide a forum where international and regional participants can meet to explore ways that technology can facilitate the implementation of confidence building in areas such as arms control, resource management, and environmental monitoring. Current sponsors of the Center are the U.S. Department of Energy (DOE) and the Arms Control and Disarmament Agency (ACDA). Arms control experts from the academic community and the U.S. Department of State also have played a major role in shaping the project.

Hands-on experience with monitoring hardware, software, and data processing and integration capabilities is provided to visitors at the Center. Current demonstration capabilities include detection and assessment technologies, data authentication and tamper-indication technologies, scale models of portal monitoring, seismic monitoring for underground nuclear tests, commercial satellite and aerial overflight imagery and analysis, pollution dispersion modeling and visualization, remote monitoring techniques, decision-making tools, and computer modeling and simulation.

The Center also functions as a data acquisition and analysis center for a number of experimental remote monitoring applications. Currently, data is received from remote monitoring experiments at nuclear fuel storage facilities in Australia and Sweden and from a remote monitoring sensor test bed that has been established at the Idaho National Engineering Laboratory. The number of remote monitoring sites is expected to grow. In this sense, the Center provides a model for regions interested in establishing their own cooperative monitoring or crisis prevention center.

Most technologies demonstrated at the Center are commercially available; all are exportable to most countries. The range of demonstrable technologies will increase as relations witlk other national laboratories, universities, and private industry are developed. It is important 
to note that Sandia's role is to help users of the Center acquire the tools to design monitoring systems to fit their needs, not to provide them with technology. Therefore, developing partnerships with industry may be needed to establish avenues for regional parties to obtain systems they design.

The Center sponsors sabbaticals, workshops, and training classes aimed at developing solutions to specific problems. It also provides facilities for collaborations on the use of technology in enhancing the effectiveness of transparency and confidence-building measures. Since its establishment, the center has conducted two major workshops on cooperative monitoring. The first workshop was developed for Middle Eastern participants and was attended by representatives from Israel, Kuwait, Egypt, Qatar, and Oman, as well as U.S. academic and government nonproliferation specialists. The second workshop, which focused on South Asia, was attended by Pakistani representatives as well as South Asia scholars from the United States. The Center also has hosted visits by numerous groups of scientists from the Former Soviet Union, a delegation from South Korea and a group from Northeast Asia studying nuclear weapon free zones. During the next year, academics and scientists from many different countries will collaborate with Center experts on formulating options for monitoring regional agreements. The Center's objective is to encourage workshop participants to take a critical interest in making their own choices, rather than to prescribe "the correct solution" for their problems. Tradeoffs between monitoring intrusiveness and system vulnerability are discussed in detail. 